\title{
TRANSOLECRANON AND LATERAL KIRSCHNER WIRE FIXATION FOR DISPLACED SUPRACONDYLAR HUMERAL FRACTURE IN CHILDREN
}

\author{
By
Abdul-Azim Ahmed Abdul-Azim, Ahmed Abd El-Hamid Shamma and Mohamed Mosa Mohamed \\ Department of Orthopedic Surgery, Faculty of Medicine, Al-Azhar University \\ Corresponding author: Abdul-Azim Ahmed Abdul-Azim, \\ E-mail: abdoeladawy365@gmail.com
}

\begin{abstract}
Background: Supracondylar fractures in children are common, accounting for $65 \%$ of all elbow fractures in children. In types II and III displaced supracondylar humeral fractures, closed reduction is difficult to achieve because of the thin bone between the coronoid and olecranon fossae as well as stripping of the periosteum. In addition, hyperflexion for maintenance of fracture reduction leads to swelling, compartment syndrome, and neurovascular compromise.
\end{abstract}

Objective: To evaluate the clinical and radiological outcome after closed reduction and pinning using a Kirschner wire inserted vertically through the olecranon and another inserted laterally for displaced supracondylar humeral fractures.

Patients and methods: A prospective case series, single Centre study conducted at Al-Azhar University Hospitals from June 2020 to May 2021. It included 20 patients with Gartland type III fracture who undergone for closed reduction and percutaneous pin fixation using two Kirschner wires, the first one was inserted vertically through the olecranon across the fracture into the metaphysis of the humerus and the second wire was inserted from the lateral column across the fracture at 30-40 degree to the opposite cortex of the humerus.

Results: Operative time ranged from 15- 30 minutes with a mean of 19.25 minutes. We counted the operative time after induction of anesthesia (including draping, reduction, wires insertion and splint application). Results were within normal range for all patients. The mean Baumann angle in the patients was 70.57 degree, and standard deviation was 3.01. Postoperatively, anteroposterior and lateral views were done, and wires were removed by 3 weeks if clinical and radiological evidence of early bone union was present and, if not, wires removal was postponded one week later. Thirteen patients $(65 \%)$ had the wires removed by 3rd week, and 7 patients (35\%), the wires were removed by 4th week with a mean of 3.35 week, and standard deviation of 0.49. Few complications occurred and all were tolerable with no effect on final outcome, and these were pin tract infection in 2 patients and loss of reduction.

Conclusion: Transolecranon and lateral Kirschner wires fixation was an effective option for displaced supracondylar humeral fractures in children.

Keywords: Transolecranon, Lateral K-wire fixation, displaced supracondylar humeral fracture. 


\section{INTRODUCTION}

Supracondylar fractures are considered the second most common type of fracture in children surpassed only by forearm fractures, accounting for $3 \%$ of all fractures in children. These fractures are caused by direct or indirect low kinetic energy traumas, such as falls, which make the occurrence of comminution, bone exposure or association with other fractures less frequent (Al-Algawy et al., 2019).

Due to the anatomical characteristics of this region and the variations in fractured fragments, immediate complications (vascular-nerve injuries, compartment syndrome) and late complications (vicious consolidation and angular deformities) can arise. The flexion-type fracture, which is caused by falling on a flexed elbow, is a rare occurrence (Chukwunyerenwa et al., 2016).

Supracondylar fracture is commonly classified according to Gartland. This system was modified by Wilkins to allow for rotational deformity: type I (undisplaced), type IIA (angulated, posterior cortex intact, no rotation), type IIB (angulated, posterior cortex intact, rotational deformity), and type III (displaced with no cortical contact) (Mallo et al., 2010).

Despite the various types of treatment, high morbidity and complications related to this type of fracture make treatment urgent and essential (Rouede et al., 2010). Types I and IIA are mainly treated in an above-elbow cast while in Type IIB and type III the preferred most common method is closed reduction and percutaneous pinning, and open reduction is indicated for irreducible fractures, vascular compromise and open injuries (Kumar and Singh, 2016).

In types II and III displaced supracondylar humeral fractures, closed reduction is difficult to maintain because of the thin bone between the coronoid and olecranon fossae as well as stripping of the periosteum. In addition, hyperflexion for maintenance of fracture reduction leads to swelling, compartment syndrome. Closed reduction and percutaneous pinning enables the cast to be kept in $<90^{\circ}$ flexion and thereby reduces the risk of complications (O'hara et al., 2010). The optimal pin configuration for displaced supracondylar fractures in children remains Controversial (Mulpuri and Wilkins, 2014).

The most common used configuration of pinning are medial and lateral crossed pinning, and lateral pinning. However, there is still controversy regarding the choice of pinning configuration and based primarily on the surgeons' preference. There are two key factors when comparing these two configurations which are the mechanical stability and the risk of iatrogenic ulnar nerve injury. Cross pinning is more biomechanically stable in fixation but it has higher risk of ulnar nerve injury during insertion of medial pin (Larson et al., 2012). Although, pinning from lateral side has negligible risk of ulnar nerve injury, is considered biomechanically less stable and having theoretical chances of loss of reduction (Eberhardt et al., 2013). Lateral K wires with Trans olecranon fossa four cortex purchase technique was described in displaced pediatric supracondylar fractures of humerus. This technique can be successfully employed even in 
comminuted and unstable fracture patterns without the fear of loss of reduction (Kasirajana et al., 2018).

Transolecranon and lateral wires is described method for configuration of the pins, using a Kirschner wire inserted vertically through the olecranon and another wire inserted laterally, as an alternative available method for fixation of displaced supracondylar humeral fractures. It has the advantage of being of an easier method, especially in cases with massive elbow swelling where the olecranon process being easily palpable. It also has the advantage of avoiding risk of ulnar nerve injury (Sharma et al., 2015).

The aim of this study was to evaluate the clinical and radiological outcome after closed reduction and pinning using a Kirschner wire inserted vertically through the olecranon and another inserted laterally for displaced supracondylar humeral fractures.

\section{PATIENTS AND METHODS}

This was a prospective case series, single Centre study conducted at Al-Azhar University Hospitals (Assiut) from June 2020 to May 2021. It included 20 patients with Gartland type III fracture.

Inclusion criteria: Children aged $2-12$ years old, and displaced types of supracondylar humerus fractures (Gartland type II \& III).

Exclusion criteria: Open fracture, irreducible fracture, vascular injury, patient presented 10 days after fracture, and refusal to provide an informed consent.

Gartland type (classification): All the patients had extension type III supracondylar humeral fractures with complete displacement.

\section{Preoperative evaluation:}

Patients were subjected to thorough preoperative evaluation both clinically and radiographically. This was done by a single observer. The medical status of the patients were revised to avoid any complications during anesthesia or surgery caused by medical illness or associated fractures (especially those in ipsilateral forearm), in addition to neurovascular examination and examination for any evidence of compartment syndrome. All the children with displaced supracondylar fractures of humerus were admitted and injured elbow was immobilized in splint with elbow in 90 to 120 degrees of extension, elevation and ice compression were advised.

Standard radiographs were done before and after surgery including an anteroposterior (AP), lateral, oblique views and forearm $\mathrm{X}$-rays were done.

All the protocols and procedures applied in this study were approved by administration department of this institution. Twenty children were treated for displaced supracondylar fracture of humerus during the study period.

\section{Surgical protocol and operative details:}

Anesthesia: Surgery was done under general anesthesia, the patient received intravenous antibiotic; first generation cephalosporins whose dose was adjusted according to the weight. (50_100 mg $/ \mathrm{kg}$ ).

Position: All the patients were positioned supine with the fractured elbow was placed over a sterile draped C-arm image intensifier which was adequate for the 
surgery due to the small size of the elbow (Figure 1).

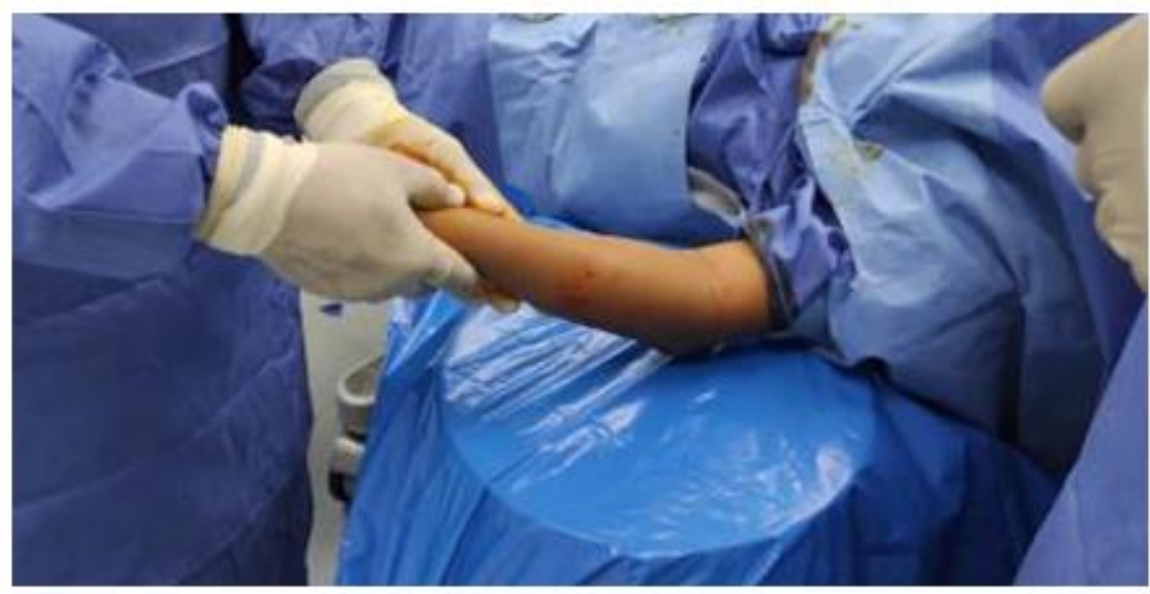

Figure (1): The elbow over the plate of image intensifier.
Reduction: Closed reduction was performed and confirmed by $\mathrm{C}$-arm image intensifier. Traction was applied with the elbow flexed at about 20 degrees to avoid the possibility of tethering neurovascular structures over an anteriorly displaced proximal fragment, with the surgeon grasping the forearm with both hands, and the assistant providing counter-traction in the axilla (Figure 2). Next, controlling rotation of the fracture occurred by the medial and lateral humeral epicondyles. The forearm was then pronated as this controlled the medial rotation, and with flexion locked the fracture in place.
This technique was adequate for reduction in all the patients of the study. Reduction acceptability was confirmed by assessment of displacement, angulation, and rotation in the coronal and sagittal planes under image intensifier (Figures 3 and 4).

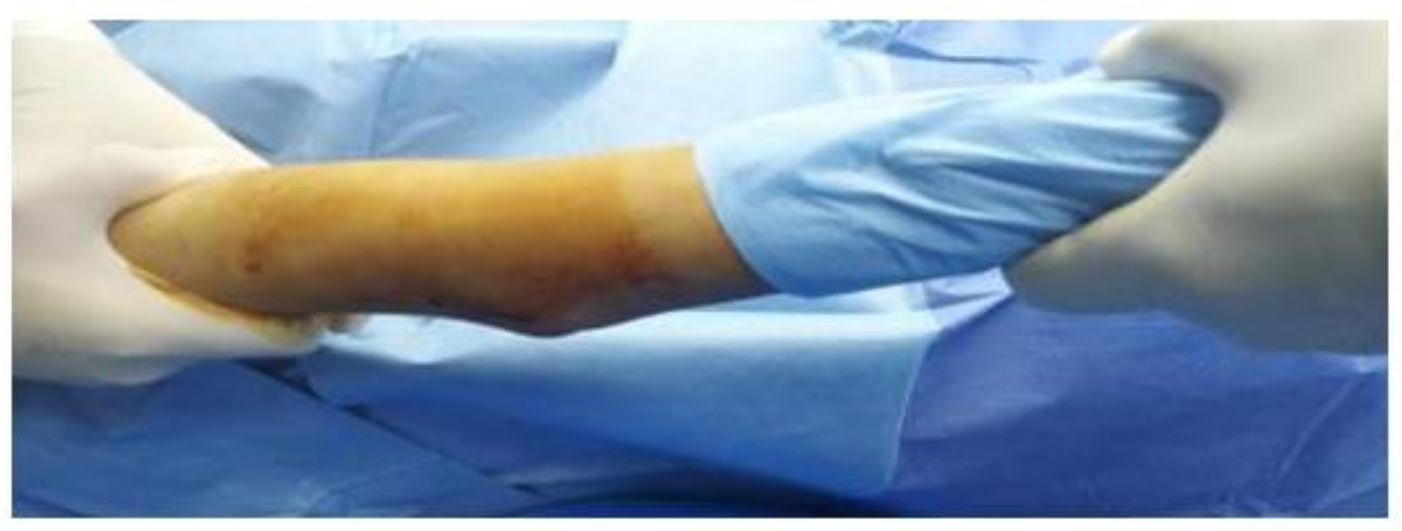

Figure (2): Manual traction of the elbow. 

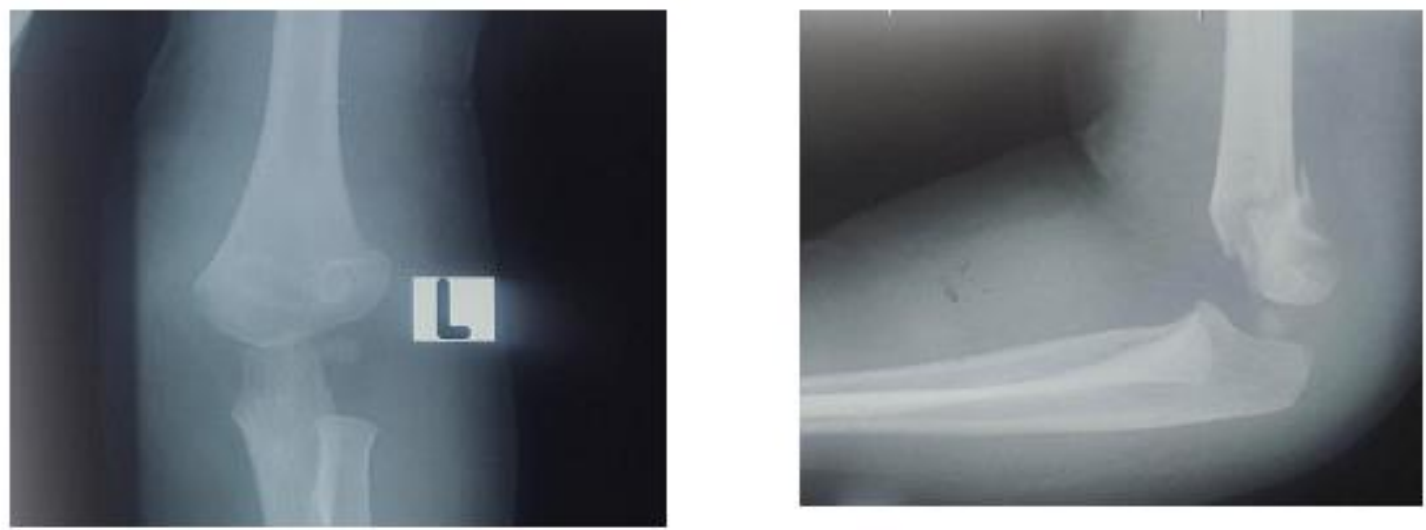

Figure (3): Preoperative x-ray.
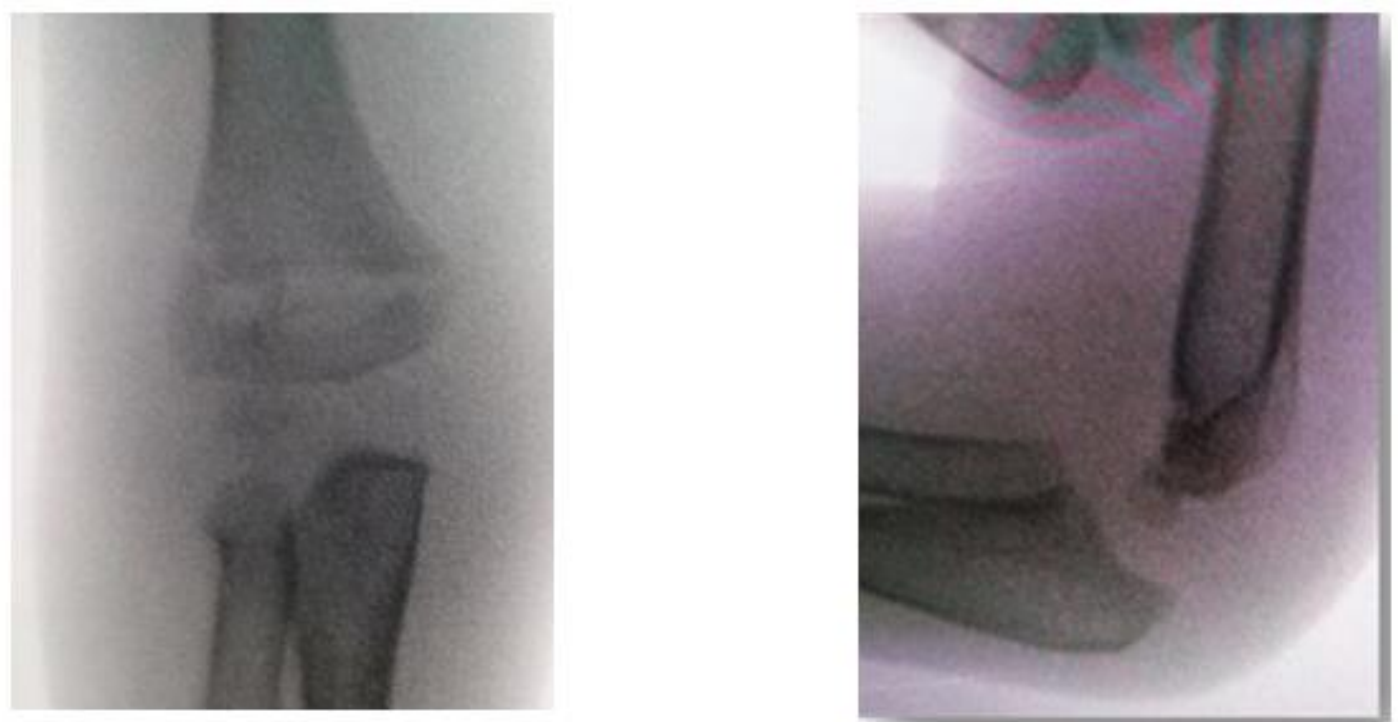

Figure (4): Reduction confirmation under image intensifier.

Pinning technique: Under complete olecranon across the fracture into the aseptic conditions, two $1.6 \mathrm{~mm}$ Kirschner metaphysis of the humerus directed wires were inserted for fixation, with elbow flexion to about $90^{\circ}$ the first one intramedullary, posterolaterally, was inserted vertically through the posteromedially or posteriorly (Figures 57).

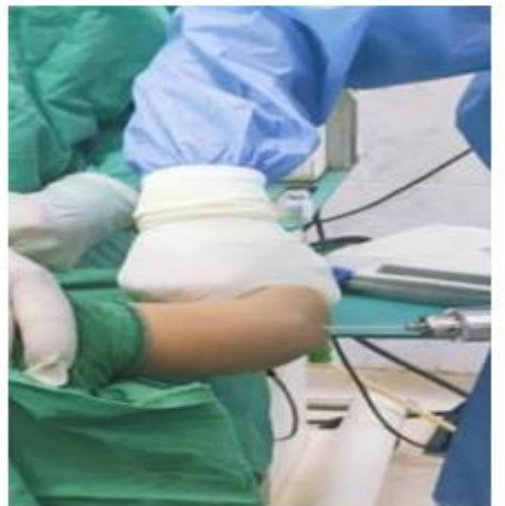

Figure (5): Transolecranon wire insertion clinically.

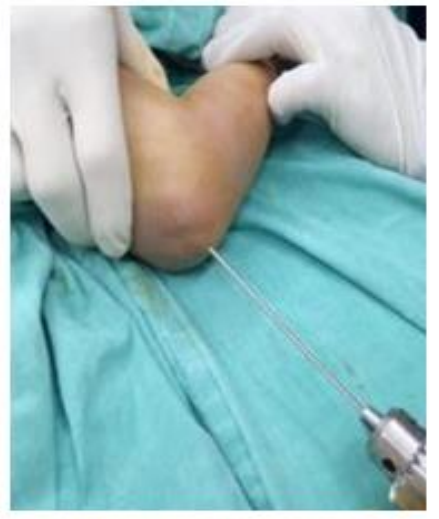

Figure (6): Transolecranon wire clinically.

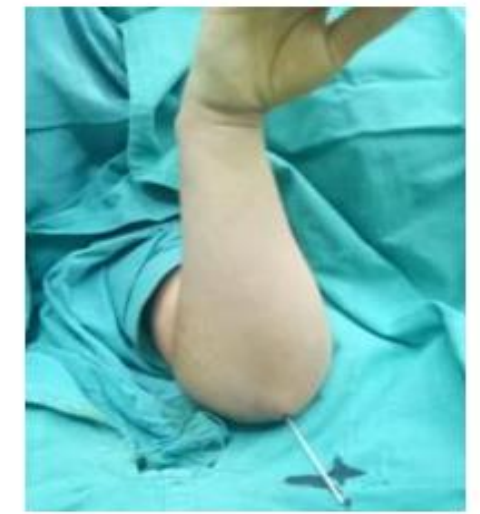



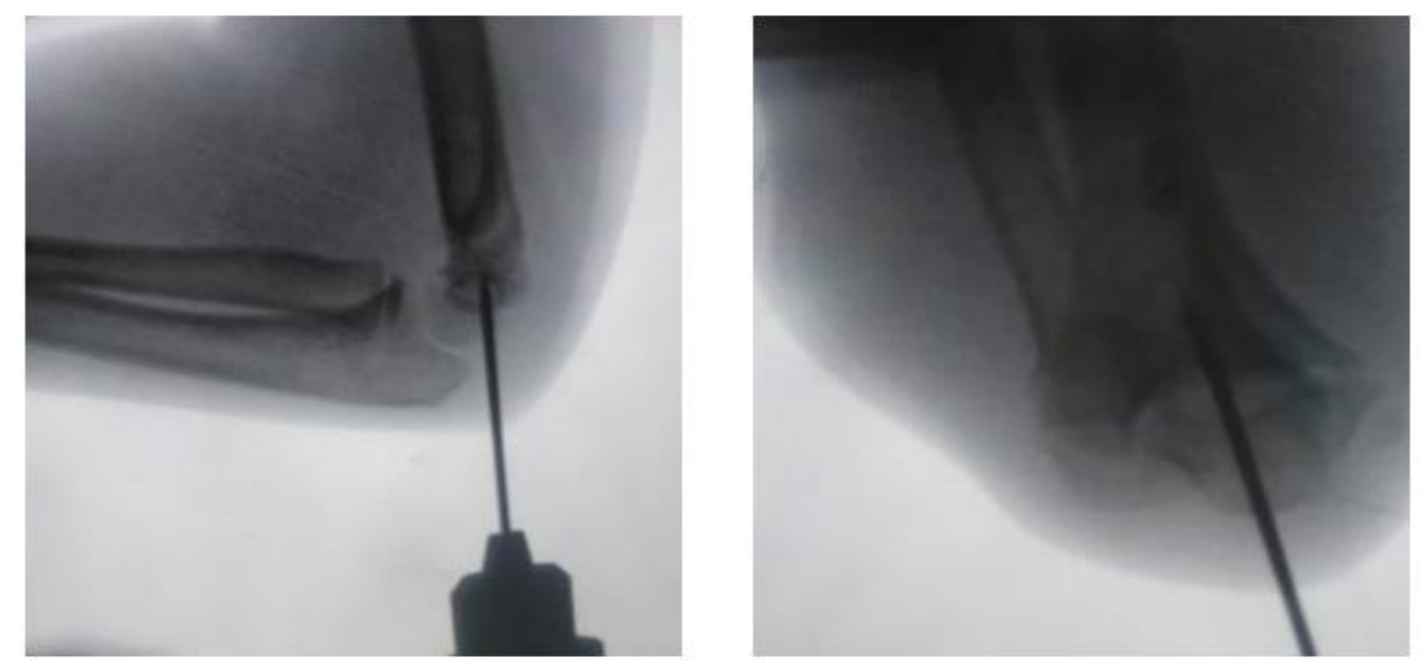

Figure (7): Transolecranon wire insertion under image intensifier

The second wire was inserted from the lateral column across the fracture at 30-40 degree to the opposite cortex of the humerus (Figure 8).
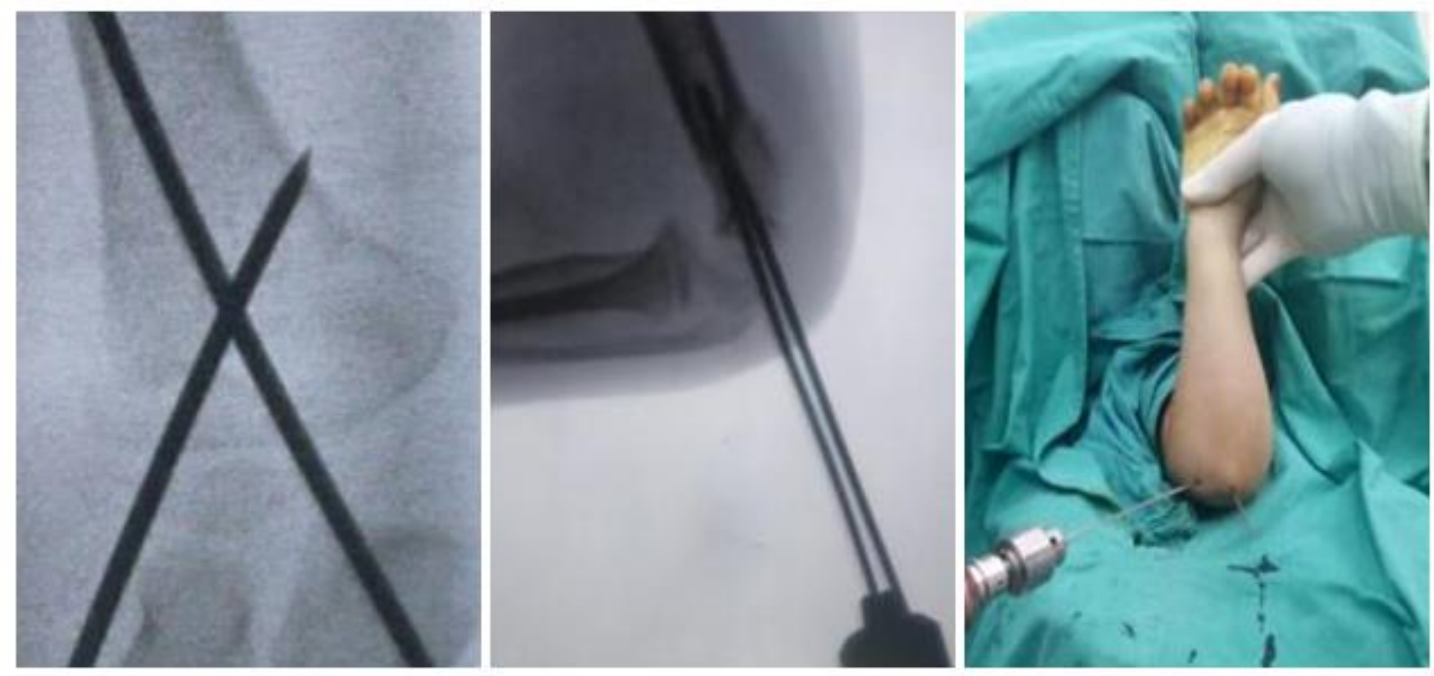

Figure (8): Lateral wire insertion.

Vascular status was assessed and, after assessment of stability, the wires were bent and cut leaving them at least 1 to 2 $\mathrm{cm}$ off the skin, to prevent migration of the wires under the skin. A sterile felt square with a slit cut into it was then placed around the wires to protect the skin. Elbow was immobilized in a plaster of Paris back slab in $90^{\circ}$ of flexion (Figures 9 and 10). 


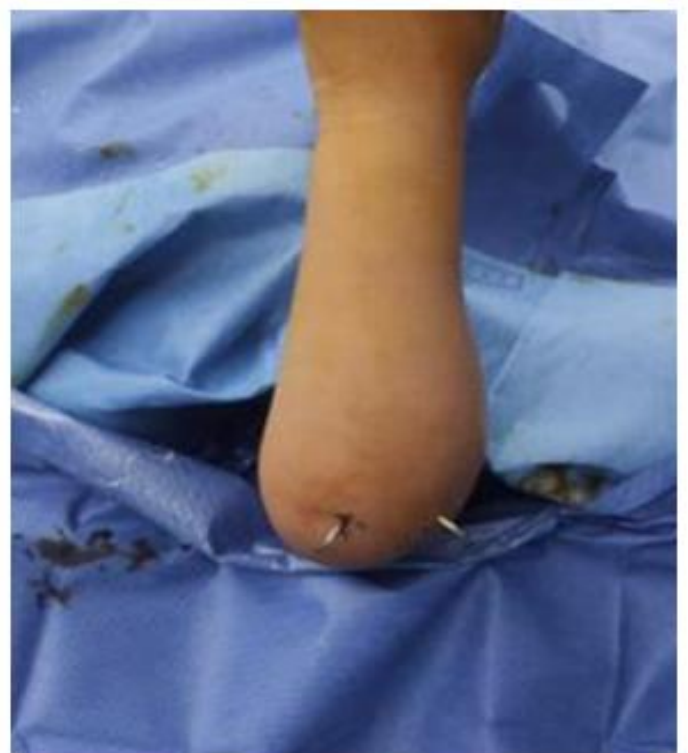

Figure (9): Wires cut and bent outside the skin

Postoperative care: All patients were given single dose of broad spectrum intravenous antibiotics; first generation cephalosporins whose dose was adjusted according to the weight (50_100 mg $/ \mathrm{kg}$ ). Followed by oral antibiotics; first generation cephalosporins $(30 \mathrm{mg} / \mathrm{kg} /$ day) in divided doses every 12 hours for 5 days. Neurovascular observation over the first 24 hours of hospitalization was done. Patients were admitted, and all of them were discharged over 24 hours and all the patients were followed up at the orthopaedic out-patient clinic and reviewed.

Follow-up and outcome measure: All the patients were followed up at the orthopedic out-patient clinic were evaluated clinically and radiographically at one week, three weeks, six weeks and three months and parents were strictly instructed not to remove the slab at home. Plaster slab and the pins were removed after 3-4 weeks. X-ray evaluation was performed by antero-posterior and lateral views of the elbow.

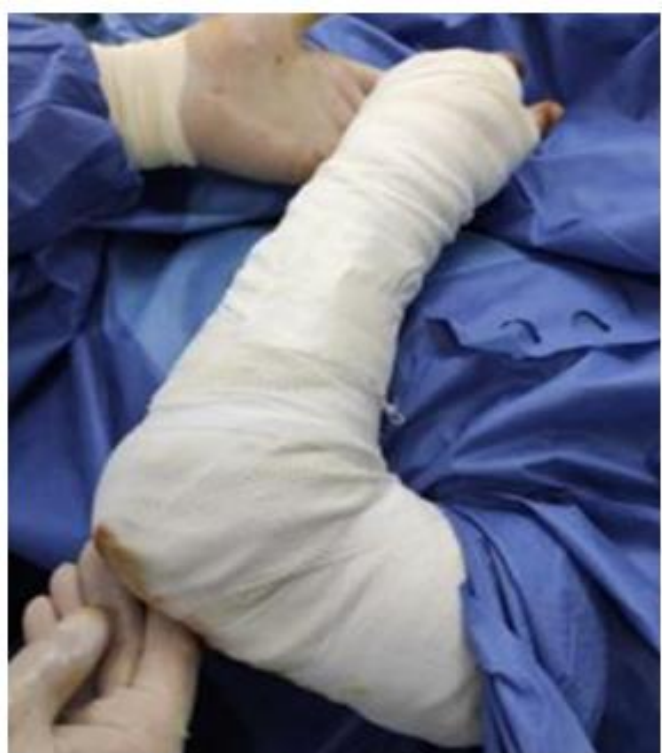

Figure (10): Above elbow slab.

Range-of-motion exercises were taught to the family, targeting gentle flexion and extension, to be started a few days after slab removal.

The child returned 6 weeks postoperatively for a range of motion check, and radiography at that time.

At the three months follow up children were evaluated for full function according to carrying angle and elbow range of motion using the criteria of Flynn.

The upper arm is not in straight alignment with the forearm, the deviation value of the straight line extending from the arm away from the forearm excellent $\left(0^{\circ}-5^{\circ}\right)$, good $\left(5^{\circ}-10^{\circ}\right)$, fair $\left(10^{\circ}-15^{\circ}\right)$, poor $\left(>15^{\circ}\right)$ when compared to normal side.

Flexion loss and extension loss values according to Flynn's criteria excellent $\left(0^{\circ}-4^{\circ}\right)$, good $\left(5^{\circ}-9^{\circ}\right)$, fair $\left(10^{\circ}-15^{\circ}\right)$, poor $\left(>15^{\circ}\right)$ when compared to normal side. 


\section{Statistical analysis:}

Categorical variables were described by number and percent (N, \%), where continuous variables were described by mean and standard deviation (SD), and median. Chi-square test used to compare between categorical variables. A twotailed $\mathrm{p}<0.05$ was considered statistically significant. All analyses were performed with the IBM SPSS 26.0 software.

\section{RESULTS}

In the period between June 2020 and May 2021 twenty patients with Gartland type III displaced supracondylar humerus fracture were treated and followed up until achieving fracture union, getting functional range of motion and recovering from any complication during the study.

The age ranged from $(3-8)$ years with a mean age 4.95 years. Eleven patients $(55 \%)$ females and 9 patients $(45 \%)$ males. Eleven patients (55\%) had RT side affection and 9 patients (45\%) had Lt side affection. The mechanisms of injury were a fall from height on an outstretched hand in 8 patients (40\%), a fall to the ground on an outstretched hand in 12 patients $(60 \%)$. Operative time range from 15- 30 minutes with mean 19.25 minutes, we counted the operative time after induction of anesthesia (including draping, reduction, wires insertion and splint application) (Table 1).

Table (1): Demographic data and operative time

\begin{tabular}{|c|c|c|}
\hline & No. $(n=20)$ & $\%$ \\
\hline $\begin{array}{l}\text { Gender } \\
\text { Male } \\
\text { Female }\end{array}$ & $\begin{array}{c}9 \\
11\end{array}$ & $\begin{array}{l}45.0 \\
55.0\end{array}$ \\
\hline $\begin{array}{c}\text { Age } \\
\text { Range (Min. - Max.) } \\
\text { Mean } \pm \text { SD } \\
\text { Median }\end{array}$ & \multicolumn{2}{|c|}{$\begin{array}{c}3-8 \\
4.95 \pm 1.61 \\
5\end{array}$} \\
\hline $\begin{array}{c}\text { Side } \\
\mathrm{Lt} \\
\mathrm{Rt} \\
\end{array}$ & $\begin{array}{c}9 \\
11\end{array}$ & $\begin{array}{l}45.0 \\
55.0\end{array}$ \\
\hline $\begin{array}{c}\text { Mode of trauma } \\
\text { FFH } \\
\text { FTG }\end{array}$ & $\begin{array}{c}8 \\
12\end{array}$ & $\begin{array}{l}40.0 \\
60.0\end{array}$ \\
\hline $\begin{array}{c}\text { Gartland type } \\
\text { III }\end{array}$ & 20 & 100.0 \\
\hline $\begin{array}{c}\text { Operative time: } \\
\text { Range (Min. - Max.) } \\
\text { Mean } \pm \text { SD } \\
\text { Median }\end{array}$ & \multicolumn{2}{|c|}{$\begin{array}{c}15-30 \\
19.25 \pm 4.38 \\
20\end{array}$} \\
\hline
\end{tabular}

*FFH=fall from height, *FTG=fall to the ground

Results were within normal range for all patients. The mean Baumann's angle in Table (2): Baumann's angle $\left(\mathrm{N}=64^{\circ}-81^{\circ}\right)$ the patients was (70.57) degree and standard deviation was (3.01) (Table 2).

\begin{tabular}{|c|c|c|c|}
\hline & Range (Min. - Max.) & Mean \pm SD & Median \\
\hline Bauman's angle & $65.2-74.4$ & $70.57 \pm 3.01$ & 71.25 \\
\hline
\end{tabular}


Postoperatively, anteroposterior and lateral views were done, and wires were removed by 3 weeks if clinical and radiological evidence of early bone union was present and, if not, wires removal was postponded one week later. Thirteen patients $(65 \%)$ had the wires removed by 3rd week, and 7 patients (35\%) the wires removed by 4 th week, with a mean of 3.35 week, and standard deviation of 0.49 (Table 3).

After wires removal, the plaster of Paris splint was retained for 2 weeks postoperatively. Intermittent active flexion extension exercises of the elbow were encouraged and lifting heavy objects by the affected limb was postponded until 12 week postoperatively.

Table (3): Time of wires removal

\begin{tabular}{|c|c|c|}
\hline Wires removal (weeks) & No. $(\mathbf{n = 2 0})$ & \% \\
\hline 3 & 13 & 65.0 \\
\hline 4 & 7 & 35.0 \\
\hline Range (Min. - Max.) & \multicolumn{2}{|c|}{$3-4$} \\
\hline Mean \pm SD & \multicolumn{2}{|c|}{$3.35 \pm 0.49$} \\
\hline Median & \multicolumn{2}{|c|}{3} \\
\hline
\end{tabular}

All patients were available for clinical evaluation and all of them were evaluated at 3 months using the Flynn grading system, based on the difference in carrying angle and range of movement between the injured and uninjured elbow. The mean follow up duration was 3 months (range from $3-3.2$ months). The mean age was 4.95 years (range from 3-8 years).
All patients are within normal range (5.7-14.7 degree), with mean carrying angle was about (9.38) degree, standard deviation was (2.12) and no one of the patients had excessive deformity of carrying angle that required correction.

There were 11 patients $(55 \%)$ excellent, 7 patients $(35 \%)$ good and 2 patient $(10 \%)$ fair, with mean ROM loss was about (5.76) degree and standard deviation was (3.59) (Table 4).

Table (4): Carrying angle and ROM loss

\begin{tabular}{|c|c|c|c|}
\hline & Range (Min. - Max.) & Mean \pm SD & Median \\
\hline Carrying angle & $5.7-14.7$ & $9.38 \pm 2.12$ & 9.5 \\
\hline Rom loss & $0.2-14.1$ & $5.76 \pm 3.59$ & 5.35 \\
\hline No. & \% & P value \\
\hline Degree of ROM loss: & 11 & 55 & \\
Excellent & 7 & 35 & 0.047 \\
Good & 2 & 10 & \\
Fair & \multicolumn{3}{|l}{} \\
\hline \multicolumn{2}{|r}{}
\end{tabular}


There were 18 patients (90\%) excellent ; 8 patients in the age group 2-4 years and 10 patients in the age group 5-8 years, 1 patients $(5 \%)$ good ; within age group 5-8 years, 1 patient $(5 \%)$ fair; this patient was within age group 5-8 years and no poor patients. With mean extension loss was about (3.13) degree and standard deviation was (1.93) (Table 5).

\section{Table (5): Extension loss}

\begin{tabular}{|c|c|c|}
\hline Extension loss & No. $(\mathbf{n = 2 0})$ & \% \\
\hline Excellent & 18 & 90.00 \\
\hline Good & 1 & 5.00 \\
\hline Fair & 1 & 5.00 \\
\hline Range (Min. - Max.) & \multicolumn{2}{|c|}{$0-7.3$} \\
\hline Mean \pm SD & \multicolumn{3}{|c|}{$2.9 \pm 1.93$} \\
\hline Median & \multicolumn{2}{|c|}{2.9} \\
\hline
\end{tabular}

There were 17 patients $(85 \%)$ excellent ; 8 patients in the age group 2-4 years and 9 patients in the age group 5-8 years, 2 patients $(10 \%)$ good; all are within age group 5-8 years, 1 patient (5\%) fair; this patient was within age group 5-8 years and no poor patients. With mean flexion loss was about (2.81) degree and standard deviation was (1.95) (Table 6).

\section{Table (6): Flexion loss}

\begin{tabular}{|c|c|c|}
\hline Flexion loss & No. $(\mathbf{n = 2 0})$ & $\%$ \\
\hline Excellent & 17 & 85.00 \\
\hline Good & 2 & 10.00 \\
\hline Fair & \multicolumn{2}{|c|}{$0.2-6.8$} \\
\hline Range (Min. - Max.) & \multicolumn{2}{|c|}{$2.81 \pm 1.95$} \\
\hline Mean \pm SD & \multicolumn{2}{|c|}{2.45} \\
\hline Median
\end{tabular}


Few complications occurred and all were tolerable with no effect on final outcome and these were pin tract infection in 2 patients and loss of reduction. One patient $(5 \%)$ has loss of reduction of the fracture. This complication appeared at 1st week follow up and this was due to slab removal and extension of the elbow by the patient at home against medical advice. The patient brought and $\mathrm{X}$ ray was done to evaluate the reduction and patient was put in above elbow cast and instructed to not remove the cast and follow up weekly in the clinic to evaluate the healing and cast state. Then at 4 weeks wire removed and the patient put in a back slab for another 2 weeks. Then at 6 weeks from the operation slab removed and the patient start intermittent active flexion extension of the elbow. 2 patients $(10 \%)$ had pin tract infection discovered during removal of the wires, for these 2 patients, pin site cleaning by removal of crusts, repeated dressing and oral antibiotic (1st generation cephalosporin) for 1 week and this led them all recover at the subsequent followup (Table 7).

Table (7): Post-operative complications

\begin{tabular}{|c|c|c|}
\hline Post-operative complications & No. $(\mathbf{n}=\mathbf{2 0})$ & \% \\
\hline Loss of reduction & 1 & 5.0 \\
\hline Pin tract infection & 2 & 10.0 \\
\hline No & 17 & 85.0 \\
\hline
\end{tabular}

\section{DISCUSSION}

The main goal of surgery in pediatric supracondylar humerus fracture is the safe creation of a construct that is stable enough to prevent axial rotation and hyper flexion and extension of the distal fragment, and thus avoid postoperative deformity (Lee et al., 2012), which has been reported to be as high as $17 \%$ (Solak and Aydn, 2013).

Closed reduction with percutaneous pin fixation for the management of displaced or angulated supracondylar humeral fractures in children has become widely adopted, but optimal pin configuration remains controversial (Mazda et al., 2010).

Open reduction is usually unnecessary, although it sometimes can be required to obtain complete reduction (Davis et al., 2010), especially in cases in which the fracture cannot be reduced because of the presence of a vascular injury (Guy et al.,
2011). There are various methods of fixation for treatment of displaced supracondylar humerus fracture in children which include lateral parallel, lateral divergent or crossed wires, and transolecranon wire configuration have been done in a single center.

This technique has been mentioned by Sharma et al. (2015) on Gartland type II \& III supracondylar humerus fractures were treated to evaluate the outcome after closed reduction and pinning using a Kirschner wire inserted laterally and another inserted vertically through the olecranon, with mean follow up duration was 13 months. Outcome did not differ significantly between patients operated on within 24 hours of injury and those operated on 2 to 5 days after injury. They concluded that transolecranon vertical and lateral Kirschner wire fixation is a viable option for displaced supracondylar 
humeral fractures in children, especially when there is massive swelling.

In the present study, 20 patients with displaced supracondylar humerus fractures were treated to assess the outcome after closed reduction and pinning using transolecranon and lateral Kirschner wires fixation especially in the presence of elbow swelling (made lateral condyle very difficult to palpate), fractures that need more than 2 lateral wires or those need medial wire for fixation. As regards to transolecranon wire trials, we obtained successful wire insertion with small number of trials with a range (1-4 trials), with a mean of 2.1, trial and standard deviation of 1.12 . The mean operative time was 19.25 minute. Outcome did not differ significantly between patients operated on within 24 hours of injury or those operated after $(\mathrm{Wu}$ et al., 2014). We have 2 patients developed superficial pin tract infection, 1 patient has loss of reduction and these complications didn't affect the final outcome.

Although the transolecranon wire limited the flexion and extension of the elbow, this did not affect the final outcome as the elbow was fixed in a plaster of Paris splint for a period of 4 weeks. The elbow had to be maintained in the same degree of flexion, while applying the plaster of Paris splint to avoid the risk of wire bending or breakage, especially the transolecranon wire. No wire backout occurred, probably because the transolecranon transarticular wire was held firmly by fixation into 4 cortices and the metaphyseal cancellous bone of humerus.
All patients regained their ROM, only 2 were referred to physiotherapy, and all other 18 patients regained their final satisfactory ROM without any need to specific therapy program. All of them given instruction to actively mobilize their elbows, and the 2 patients that were referred to physiotherapy were reluctant to actively mobilize their elbows.

No radiological evidence of articular damage occurred because smooth pins were used. No infective arthritis occurred despite the Kirschner wire across the joint, probably because of aseptic precautions intra and post-operatively.

The limitations of this study was the lack of a control group for comparison, short duration of follow up and lack of biomechanical study of the stability of the construct.

\section{CONCLUSION}

Transolecranon with lateral Kirschner wires fixation was an effective option that provides good stability with little number of trials in management of supracondylar fracture of the humerus in children, and the risk of nerve injury, or fishtail deformity (Dissolution of distal humerus) were avoided.

\section{REFERENCES}

1. Al-Algawy AAH, Aliakbar AH and Witwit IH. (2019): Open versus closed reduction and K-wire fixation for displaced supracondylar fracture of the humerus in children. European Journal of Orthopaedic Surgery \& Traumatology, 29(2): 397-403.

2. Chukwunyerenwa C, Orlik B, El-Hawary R, Logan $K$ and Howard JJ. (2016): Treatment of flexion-type supracondylar fractures in children: the 'push-pull'method for closed reduction and percutaneous $\mathrm{K}$-wire 
fixation. Journal of Pediatric Orthopaedics, 25(5):412-416.

3. Davis RT, Gorczyca JT and Pugh K (2010): Supracondylar humerus fractures in children: comparison of operative treatment methods. Clinical Orthopaedics and Related Research, 376: 49-55.

4. Eberhardt O, Fernandez F, Ilchmann T and Parsch K (2013): Cross pinning of supracondylar fractures from a lateral approach. Stabilization achieved with safety. Journal of Children's Orthopaedics, 1(2):127133.

5. Guy SP, Ponnuru RR, Gella $S$ and Tulwa N. (2011): Lateral entry fixation using three divergent pins for displaced paediatric supracondylar humeral fractures. International Scholarly Research Notices, 11: 158-163.

6. Kasirajana $S$, Govindasamy $R$, Sathishb BR, Meleppurama JJ. (2018): Trans-olecranon fossa four-cortex purchase lateral pinning in displaced supracondylar fracture of the humerus - A prospective analysis in 48 children. Revista Brasileira de Ortopedia (English Edition), 53(3): 342-349.

7. Kumar V and Singh A. (2016): Fracture supracondylar humerus: A review. Journal of Clinical and Diagnostic Research, 10(12): 16.

8. Larson L, Firoozbakhsh K, Passarelli R and Bosch P. (2012): Biomechanical analysis of pinning techniques for pediatric supracondylar humerus fractures. Journal of Pediatric Orthopaedics, 26(5):573-578.

9. Lee YH, Lee SK, Kim BS, Chung MS, Baek GH, Gong HS and Lee JK. (2012): Three lateral divergent or parallel pin fixations for the treatment of displaced supracondylar humerus fractures in children. Journal of Pediatric Orthopaedics, 28(4):417422.

10. Mallo G, Stanat SJ and Gaffney J. (2010): Use of the Gartland classification system for treatment of pediatric supracondylar humerus fractures. Orthopedics, 33(1): 123-129.

11. Mazda K, Boggione $C$, Fitoussi $F$ and Pennecot G. (2010): Systematic pinning of displaced extension-type supracondylar fractures of the humerus in children: a prospective study of 116 consecutive patients. The Journal of Bone and Joint Surgery British, 83(6): 888-893.

12. Mulpuri K and Wilkins K. (2012): The treatment of displaced supracondylar humerus fractures: evidence-based guideline. Journal of Pediatric Orthopaedics, 32: 143152.

13. O'hara L, Barlow $J$ and Clarke NM. (2010): Displaced supracondylar fractures of the humerus in children: audit changes practice. The Journal of Bone and Joint Surgery British, 82(2):204-210.

14. Rouede RS, Giordano $V$ and Amaral NP (2010): Surgical treatment of displaced supracondylar fractures of the humerus in children: analysis of the results of 20 cases. Rev Bras Ortop., 10:105-110.

15. Sharma A, Kahal $K$ and Sharma S. (2015): Transolecranon and lateral Kirschner wire fixation for displaced supracondylar humeral fracture in children. Journal of Orthopaedic Surgery, 23(3):319-322.

16. Solak $S$ and Aydn E. (2013): Comparison of two percutaneous pinning methods for the treatment of the pediatric type III supracondylar humerus fractures. Journal of Pediatric Orthopaedics, 12(5):346-349.

17. Wu W, Li X, Shi Q, Dai S, Tan W and Hu C. (2014): Minimally invasive treatment of Gartland type III humerus supracondylar fracture in children. Journal of Southern Medical University, 34(9):1351-1354. 
علاج الكسور المز احة بأعلي اللقمتين بعظمة العضد عند

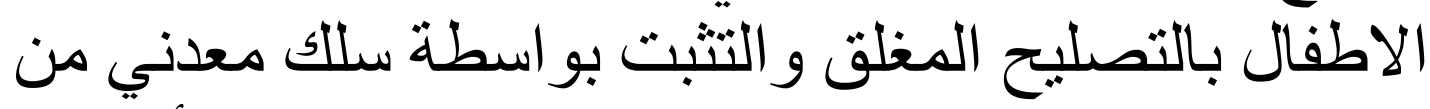
خلال النتوء الزجي لعظمة الزند والهر الزم من اللقمة الأوحشية لعظمة العضد لزد آلخ

عبدالعظيم أحمد عبدالعظيه, أحمد عبدالحميد شما, محمد موسي محمد قسم جراحة العظام, كلية الطب، جامعة الأزهر

E-mail: abdoeladawy365@gmail.com

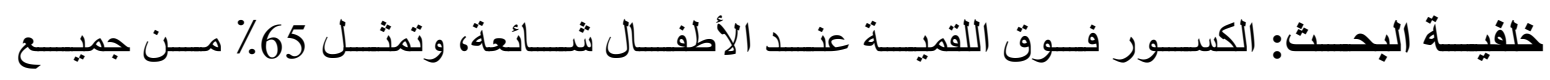

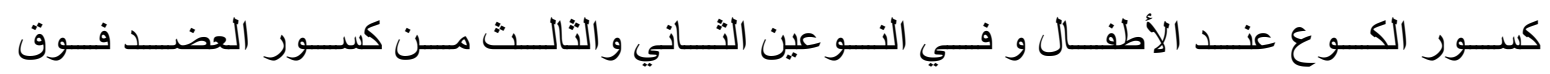

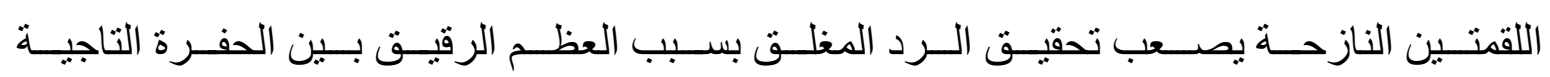

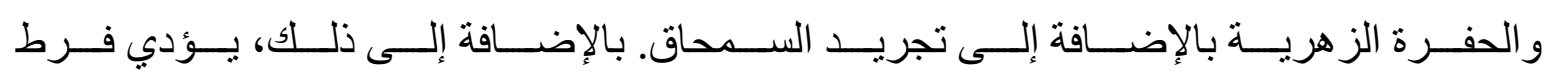

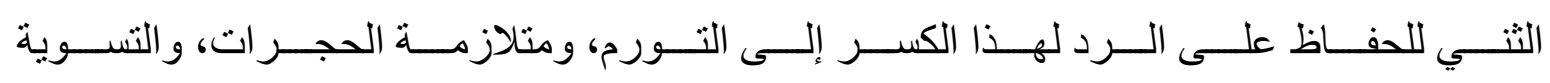
الو عائية العصبية.

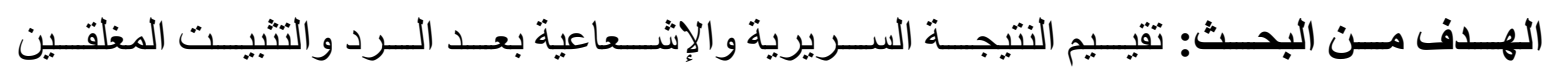

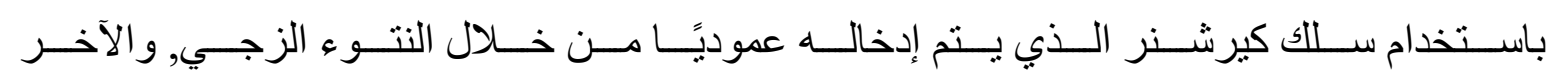
يتم إدخاله بشكل جانبي لكسور العضد فوق اللقمتين النازحة.

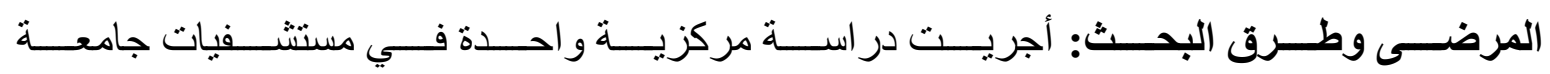

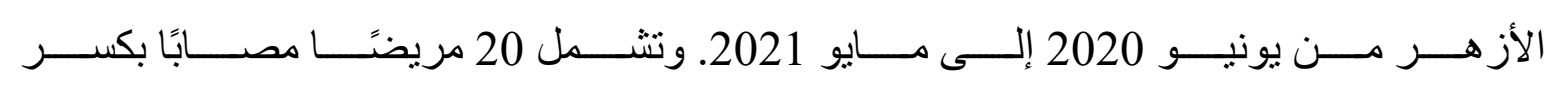

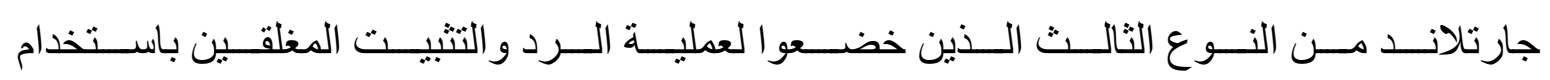

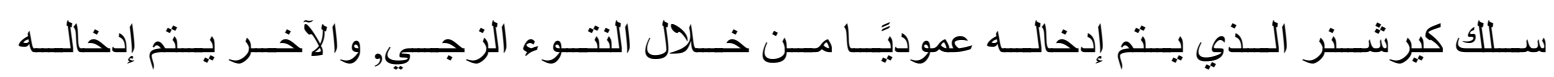
بشكل جانبي.

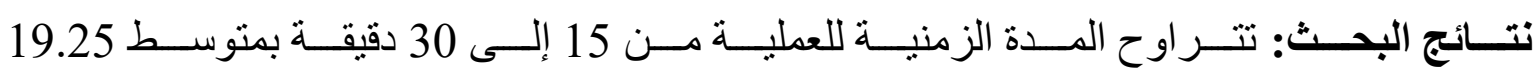

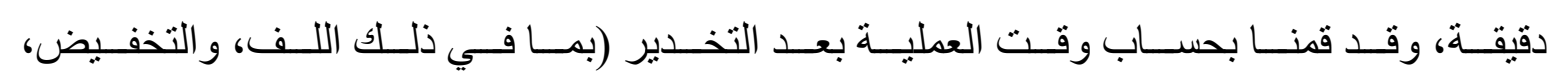

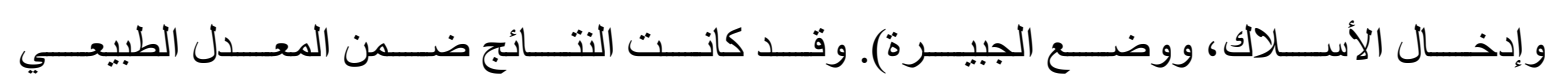

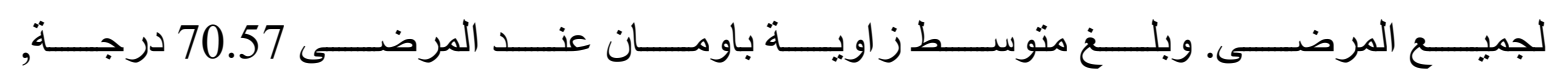


TRANSOLECRANON AND LATERAL KIRSCHNER WIRE FIXATION... 2757

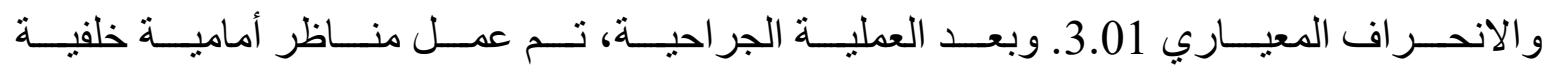

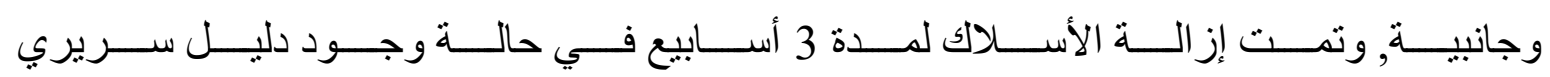

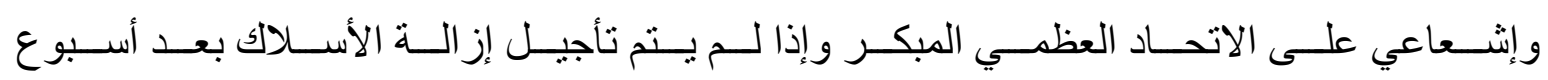

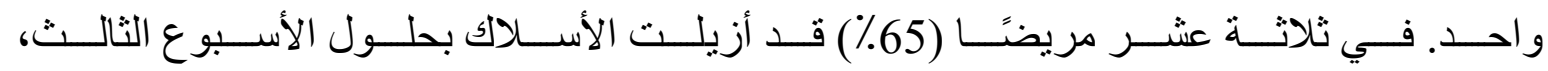

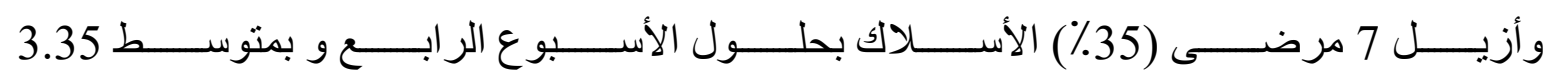

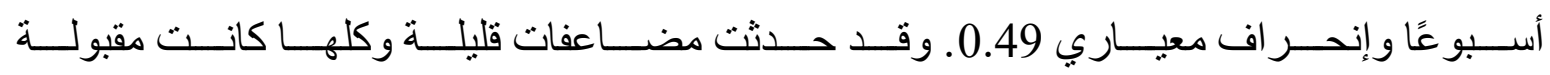

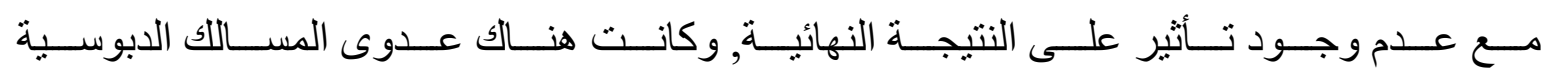
في مريضين وفقدان الرد في احدي المرضي.

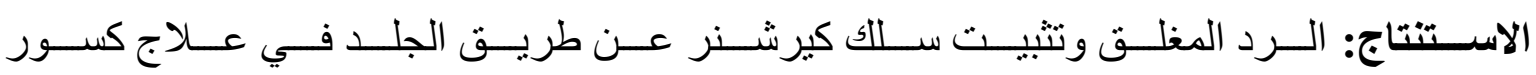

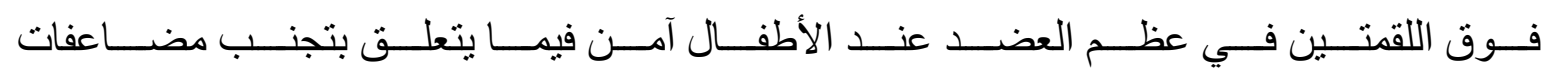

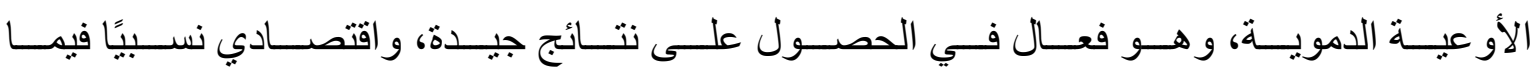
يتعلق بالاسنثفاء.

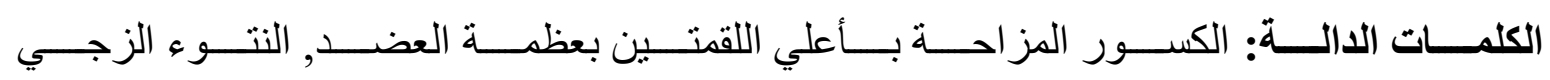
لعظمة الزند, سلك من اللقمة الأوحثية لعظمة العضد. 